Research Article

\title{
Determinants of Virologic Failure among Adult HIV Patients on First-Line Antiretroviral Therapy at Waghimra Zone, Northern Ethiopia: A Case-Control Study
}

\author{
Abrham Emagnu, ${ }^{1}$ Zenahebezu Abay, ${ }^{2}$ Abera Balcha Bulti, ${ }^{2}$ and Yaregal Animut $\mathbb{D}^{3}$ \\ ${ }^{1}$ Waghimra Zone Health Department, Sekota, Ethiopia \\ ${ }^{2}$ Department of Internal Medicine, School of Medicine, College of Medicine and Health Sciences, University of Gondar, \\ Gondar, Ethiopia \\ ${ }^{3}$ Department of Epidemiology and Biostatistics, Institute of Public Health, College of Medicine and Health Sciences, \\ University of Gondar, Gondar, Ethiopia \\ Correspondence should be addressed to Yaregal Animut; yaregalae@gmail.com
}

Received 14 February 2020; Revised 30 May 2020; Accepted 29 June 2020; Published 29 August 2020

Academic Editor: Carol J. Burns

Copyright (c) 2020 Abrham Emagnu et al. This is an open access article distributed under the Creative Commons Attribution License, which permits unrestricted use, distribution, and reproduction in any medium, provided the original work is properly cited.

\begin{abstract}
Introduction. The primary goal of antiretroviral therapy (ART) is to reduce the viral load in HIV-infected patients to promote quality of life, as well as to reduce HIV-related morbidity and mortality. A high rate of virologic failure was reported in Waghimra Zone, Northwest Ethiopia, in viral load assessment conducted among HIV-infected patients on ART in the Amhara region. However, there is limited evidence on the determinants of virological failure in the study area. This study aimed to identify the determinants of virological failure among HIV-infected patients on antiretroviral therapy in Waghimra zone, Northern Ethiopia, 2019. Methods. An institutional-based unmatched case-control study was conducted from May 21 to June 30, 2019. Cases were people living with HIV (PLHIV) on ART who had already experienced virological failure; controls were those without virological failure. Data were extracted from 92 cases and 184 controls through chart review using a pretested and structured checklist. The data were entered using Epi Info version 7 and exported to SPSS version 20 for analysis. A multivariate logistic regression analysis was carried out to identify factors associated with virological failure, and variables with a $P$ value $<0.05$ were considered statistically significant. Results. This study revealed that poor adherence to ART (adjusted odds ratio (AOR) $=4.24,95 \%$ confidence interval (CI): 2.17, 8.31), taking ART for longer than five years ( $\mathrm{AOR}=3.11,95 \% \mathrm{CI}: 1.17,8.25)$, having drug toxicity $(\mathrm{AOR}=3.34$, 95\% CI: 1.54, 7.23), age of PLHIV $\geq 35$ years $(\mathrm{AOR}=2.45,95 \% \mathrm{CI}: 1.29,4.64)$, and recent CD4 count $<200 \mathrm{cells} / \mathrm{mm}^{3}(\mathrm{AOR}=3.06$, 95\% CI: $1.52,6.13)$ were factors associated with virologic failure. Conclusion and Recommendation. This study showed that poor adherence to treatment, longer duration on ART, experiencing drug toxicity, older age, and recent CD $4<200$ cell $/ \mathrm{mm}^{3}$ are factors that increase the risk of virologic failure.
\end{abstract}

\section{Introduction}

Since the start of the human immunodeficiency virus (HIV) epidemic, 74.9 million people have been infected, and 32 million people have died from acquired immunodeficiency syndrome- (AIDS-) related illnesses. In 2018, 37.9 million people were living with HIV/AIDS globally, from which 95\% were adults. About 1.7 million people became newly infected, and one million died from AIDS-related illness. Of all people living with the human immunodeficiency virus
(PLHIV), 62\% were accessing treatment and 53\% were virally suppressed in 2018 [1]. Africa contains most of the disease and is largely affected by the epidemic. In Eastern and Southern Africa, 20.6 million people were living with HIV in 2018, which accounts for 54\% of global total HIV infection. From all PLHIV in this region, $67 \%$ had access to antiretroviral therapy (ART) [1].

In Ethiopia, the prevalence of HIV among adults was $0.9 \%$ and varying across regions with the highest prevalence observed in Gambella 4.8\% followed by Addis Ababa 3.4\% in 
2016 [2]. In Amhara regional state, there were about 187,975 PLHIV, contributing to $30 \%$ of the PLHIV population of the country [3]. ART was introduced in Ethiopia in 2003, and in 2005, the Ethiopian Government launched free access for ART in different health sectors to improve the quality of life of PLHIV [4].

The primary goal of ART is to achieve long-term durable suppression of HIV replication, which gives immunologic and clinical benefits, and in turn leads to a reduction in morbidity and mortality and improved quality of life. Unable to suppress HIV viral replication results in treatment failure and development of antiretroviral (ARV) drug resistance [5]. The World Health Organization (WHO) recommends the use of routine HIV viral load (VL) testing as the preferred approach for PLHIV on ART to monitor treatment response and diagnose treatment failure. While routine virologic monitoring is the standard of care in industrialized countries, targeted VL testing is still practiced in some resource-limited settings to confirm immunologic and/or clinical failure before switching to second-line treatment [5].

Previous studies suggest some of the factors that may be associated with virologic failure. Studies in Africa showed that men have less HIV virologic suppression than women [6-8]. Age [9], income [10], and educational status [11] are some of the sociodemographic factors associated with virologic failure. Similarly, clinical and medication-related factors such as drug adherence [12, 13], drug toxicity [14], cluster of differentiation 4 (CD4) count $[15,16]$, tuberculosis (TB) coinfection [16-18], duration of stay on ART [11], WHO clinical stage [15], and anemia [19] are mentioned as determinants for viral suppression.

According to the National Consolidated Guidelines for Comprehensive HIV Prevention, Care, and Treatment of Ethiopia, the recommended first-line regimens for adults are $\mathrm{TDF}+3 \mathrm{TC}+\mathrm{DTG}, \mathrm{AZT}+3 \mathrm{TC}+\mathrm{EFV} / \mathrm{NVP}, \mathrm{TDF}+3 \mathrm{TC}+$ $\mathrm{EFV} / \mathrm{NVP}$, or $\mathrm{ABC}+3 \mathrm{TC}+\mathrm{EFV} / \mathrm{NVP}$, and the second-line regimens could be $\mathrm{TDF}+3 \mathrm{TC}+\mathrm{LPV} / \mathrm{r}$ or $\mathrm{ATV} / \mathrm{r}$ or $\mathrm{AZT}+3 \mathrm{TC}+\mathrm{LPV} / \mathrm{r}$ or $\mathrm{ATV} / \mathrm{r}$ depending on the regimen type used in the first-line [20].

The government of Ethiopia has adopted the global goal to attain the 90-90-90 targets: 90 percent of PLHIV know their status, 90 percent of PLHIV who know their status are on treatment (ART), and 90 percent of PLHIV on treatment have attained viral suppression. In Ethiopia, as of May 2018, $79 \%$ of PLHIV knew their status; $71 \%$ of eligible PLHIV are on ART, and $87 \%$ of those on ART have attained viral suppression [3]. A VL assessment that was conducted in 2018 in the Amhara region by the regional health bureau revealed that $18 \%$ of PLHIV on first-line ART in Waghimra Zone had a virologic failure [21], which is the highest in the region. Therefore, this study aimed to determine factors related to virologic failure among adult PLHIV in the Waghimra zone.

\section{Methods and Materials}

2.1. Study Design and Setting. An institutional-based unmatched case-control study was conducted from May 21 to
June 30, 2019, in the Waghimra zone. Waghimra zone is a special administrative zone in Amhara regional state. Sekota is the administrative capital of the Waghimra zone and is located $715 \mathrm{~km}$ far from Addis Ababa, the capital of Ethiopia, and $560 \mathrm{~km}$ from Bahir Dar, the capital city of Amhara regional state. Waghimra zone has 31 health centers and 3 district hospitals and provides health care services for more than 600,000 residents. Currently, 11 health centers and 1 district hospital provides comprehensive HIV care. The regional health bureau conducted a VL test for 512 PLHIV in 6 randomly selected health facilities ( 5 health centers and 1 primary hospital) in 2018. A total of 1,984 PLHIV were enrolled in these health facilities: 195 in Amdework Heath Center (HC), 163 in Chila HC, 278 in Asketema HC, 166 in Hamusit HC, 292 in Tsisika HC, and 890 in Tefera Hailu Hospital.

2.2. Population and Sample. The sample size of the study was calculated by Epi Info ${ }^{\mathrm{TM}} 7$ software Statcalc program using the following assumptions: key predictor of virological failure (age) from a previous study, proportion of controls exposed $47.7 \%$, odds ratio 2.52 [11], 5\% level of significance, $80 \%$ power of the study, and 1:2 case to control ratio. Therefore, the calculated sample size was 197 (66 cases and 131 controls). However, to improve the power of the study, all of the cases (92) and comparable controls (184) were included in the study. Controls were selected by using simple random sampling techniques. All adult PLHIV aged $\geq 15$ years who have at least two VL measurements after initiation of first-line ART in the Waghimra zone were included in the study. PLHIV who have taken the first-line ART for less than 6 months were excluded. All HIV-infected adults whose plasma VL is $\geq 1,000$ copies/mL in two consecutive VL measurements within a 3-month interval with adherence support between measurements were defined as cases (virologic failure), while study participants with a VL level of $<1,000$ copies/mL were considered as controls [5]. All 92 cases found from 5 health centers and 1 primary hospital were included in the study. The case of virologic failure distributions were 9 from Amdework HC, 8 from Chila HC, 15 from Asketema HC, 6 from Hamusit HC, 14 from Tsisika HC, and 40 from Tefera Hailu Hospital.

2.3. Data Collection Tools and Procedure. Data were extracted from the clients' medical records using a pretested structured checklist adapted from the Ethiopian Federal Ministry of Health ART clinic intake and follow-up form. The data were collected by 5 trained health professionals. The principal investigator and supervisors closely monitored the whole data collection process.

2.4. Assessment of Drug Toxicity and Adherence. When drug toxicity is suspected, the clinical condition is assessed to identify whether it is due to ARV toxicities, other drugs, or other illness including new opportunistic infections. The responsible ARV drug will be identified, and the severity of toxicity will be assessed using the toxicity grading matrix. 
Then, drug regimens or single-agent substitutions may be required [20]. In our study, we have included all the recorded toxicities irrespective of the severity.

Adherence status was assessed based on the reported number of pills taken in the last one month divided by the number of prescribed pills multiplied by $100 \%$. Clients who reported an intake of $\geq 95 \%$ of the prescribed medication were considered good adherent; those with a reported intake of $<95 \%$ were classified as poor adherent [20].

2.5. Data Processing and Analysis. Data were entered using Epi Info version 7 and exported to Statistical Package for Social Sciences (SPSS) version 20 software for analysis. Descriptive statistics, including frequencies and percentages, were used to describe demographic, clinical, hematologic, and medication-related characteristics of the study participants. Bivariate analysis was carried out for all independent variables with an outcome variable, and variables with $P$ value $\leq 0.2$ were entered into a multivariable logistic regression model to identify the independent determinants of virological failure. Finally, the adjusted odds ratio with $95 \%$ CI was determined, and variables with $P$ value $<0.05$ were considered significant.

\section{Results}

3.1. Sociodemographic Characteristics. A total of $276 \mathrm{HIV}-$ positive individuals (92 cases and 184 controls) who have at least 6 months ART follow-up participated in the study. More than half $(55.1 \%)$ of the study participants were females. Two-thirds, $122(66.3 \%)$ of controls and $44(44.6 \%)$ of cases, were under the age of 35 years. Over half $(57.1 \%)$ of controls and $40.2 \%$ cases were married. More than half $(58.7 \%)$ of cases and $52.2 \%$ controls were urban dwellers. The majority of cases (57.6\%), as well as controls (64.1\%), have no formal education (Table 1).

3.2. Hematological and Immunological Factors. In this study, $65(70.7 \%)$ of the cases and $113(61.4 \%)$ of the controls had $<200$ cells $/ \mathrm{mm}^{3}$ CD 4 count at baseline, while $40(43.5 \%)$ of the cases and $38(20.7 \%)$ of the controls had current CD4 count of $<200$ cells $/ \mathrm{mm}^{3}$. Baseline white blood cell (WBC) count of the majority of cases $(67(72.8 \%))$ and controls (130 $(70.7 \%))$ was laid between $4 \times 10^{3}$ and $10.9 \times 10^{3}$ cells $/ \mathrm{mm}^{3}$. The baseline hemoglobin level was greater than $12 \mathrm{~g} / \mathrm{dl}$ for 52 $(56.5 \%)$ of cases and $110(59.8 \%)$ of controls (Table 2 ).

3.3. Medication-Related Factors. In this study, 58 (63.1\%) of the cases and 98 (53.3\%) of the controls were on AZT-based first-line ART regimen. The median period that PLHIV had been on ART was 8 years (IQR 6 to 10 years), and $82(89.1 \%$ ) of the cases and $134(72 \%)$ of the controls stayed on ART for more than five years. Thirty-two $(34.8 \%)$ of cases and 35 (19\%) of controls faced drug toxicity, while $29(31.5 \%)$ of cases and $50(27.2 \%)$ of controls had a history of regimen change on first-line ART drugs. More than half (53.3\%) of the cases and $29(15.8 \%)$ of the controls were poorly adherent to ART. The majority of cases 72 (78.3) and controls 134 (72.8) had a history of cotrimoxazole preventive therapy (CPT) use (Table 3).

3.4. Clinical Characteristics. According to the WHO clinical stage classification, 55 (59.8\%) of the cases and 64 (34.8\%) of the controls were classified as stage III at baseline. From the participants, $25(27.2 \%)$ of cases and 17 (9.2\%) of the controls had a history of TB coinfection, while 34 (37\%) of cases and $25(13.6 \%)$ of the controls had a history of opportunistic infection other than TB. The baseline body mass index (BMI) was $<16 \mathrm{~kg} / \mathrm{m}^{2}$ for $42(45.7 \%)$ of cases and 46 (25\%) of controls (Table 4 ).

3.5. Determinants of Virological Treatment Failure. In this study, age, current CD4 count, duration on ART, drug toxicity, and ART medication adherence were factors significantly associated with virologic failure.

The likelihood of developing virological failure for PLHIV aged $\geq 35$ years was 2.45 times $(A O R=2.45,95 \% \mathrm{CI}$ : $1.29,4.64)$ more likely as compared with their younger counterparts. The odds of developing virologic failure among PLHIV who had less than 200 cells $/ \mathrm{mm}^{3}$ in recent CD4 count were 3 times $(\mathrm{AOR}=3.06,95 \% \mathrm{CI}: 1.52,6.13$ ) more likely as compared to clients with baseline CD4 count $\geq 200$ cells $/ \mathrm{mm}^{3}$. Participants who stayed five years and above on first-line ART were also 3 times $(\mathrm{AOR}=3.11$, $95 \%$ CI: $1.17,8.25$ ) more likely to develop virologic failure as compared to those who stayed for less than five years. Clients who had experienced drug toxicity were 3.34 times $(\mathrm{AOR}=3.34,95 \% \mathrm{CI}: 1.54,7.23)$ more likely to have virologic failure as compared to those who had no history of drug toxicity. Clients who were not adherent to their ART drugs were 4 times (AOR 4.24, 95\% CI: 2.17, 8.31) more likely to have virologic failure as compared to those who were adherent to their treatment (Table 5).

\section{Discussion}

This study aimed to assess the determinants of virological failure among adult PLHIV on first-line ART and showed that older age ( $\geq 35$ years), low recent CD4 count $\left(<200 \mathrm{~mm}^{3}\right)$, longer duration of stay on ART, having history of ART drug toxicity, and poor adherence to ART were found to have increased odds of virological failure.

This study revealed that PLHIV aged $\geq 35$ years were 2.45 times more likely to develop virologic failure as compared with their younger counterparts. This finding is supported by studies conducted in Ethiopia [22], Mozambique [23], and the United States of America [24]. On the contrary, the odds of virological failure decreased with increased age as evidenced by the studies conducted in Uganda [18], Canada [25], and Gondar, Ethiopia [11]. The possible reasons for higher odds of virologic failure among older clients maybe that old PLHIV tend to develop drug toxicity and age-related kidney and liver function reduction, which may result in impaired drug elimination [26, 27]. 
TABLE 1: Sociodemographic characteristics of PLHIV on ART at Waghimra zone health institution ART clinic, Northern Ethiopia, in 2019 $(n=276)$.

\begin{tabular}{|c|c|c|c|c|}
\hline Variable & Cases $(n \%)$ & Control $(n \%)$ & Chi-square $\left(X^{2}\right)$ & $P$ value \\
\hline \multicolumn{5}{|l|}{ Age (years) } \\
\hline$<35$ & $41(44.6)$ & $122(66.3)$ & 11.98 & 0.001 \\
\hline$\geq 35$ & $51(55.4)$ & $62(33.7)$ & & \\
\hline \multicolumn{5}{|l|}{ Sex } \\
\hline Male & $43(46.7)$ & $81(44)$ & 0.183 & 0.669 \\
\hline Female & $49(53.3)$ & $103(56)$ & & \\
\hline \multicolumn{5}{|l|}{ Residence } \\
\hline Urban & $54(58.7)$ & $96(52.2)$ & 1.05 & 0.305 \\
\hline Rural & $38(41.3)$ & $88(47.8)$ & & \\
\hline \multicolumn{5}{|l|}{ Occupation } \\
\hline Farmer & $21(22.8)$ & $53(28.8)$ & 6.83 & 0.234 \\
\hline Housewife & $22(23.9)$ & $37(20.1)$ & & \\
\hline Government & $14(15.2)$ & $28(15.2)$ & & \\
\hline Nongovernment & $2(2.2)$ & $16(8.7)$ & & \\
\hline Private & $10(10.9)$ & $14(7.6)$ & & \\
\hline Unemployed & $23(25)$ & $36(19.6)$ & & \\
\hline \multicolumn{5}{|l|}{ Religion } \\
\hline Orthodox & $90(97.8)$ & $180(97.8)$ & 0.60 & 0.741 \\
\hline Muslim & $2(2.2)$ & $4(2.2)$ & & \\
\hline \multicolumn{5}{|l|}{ Marital status } \\
\hline Married & $37(40.2)$ & $105(57.1)$ & 8.08 & 0.044 \\
\hline Single & $36(39.1)$ & $45(24.5)$ & & \\
\hline Widowed & $5(5.4)$ & $8(4.3)$ & & \\
\hline Divorce & $14(15.2)$ & $26(14.1)$ & & \\
\hline \multicolumn{5}{|l|}{ Educational status } \\
\hline No formal education & $53(57.6)$ & $118(64.1)$ & 2.02 & 0.363 \\
\hline Primary & $22(23.9)$ & $31(16.9)$ & & \\
\hline Secondary and above & $17(18.5)$ & $35(19)$ & & \\
\hline
\end{tabular}

TABLE 2: Hematologic and immunological findings on ART clients at Waghimra zone health institution ART clinic, Northern Ethiopia, in $2019(n=276)$.

\begin{tabular}{|c|c|c|c|c|}
\hline Variable & Cases $(n \%)$ & Control $(n \%)$ & Chi-square $\left(X^{2}\right)$ & $P$ value \\
\hline \multicolumn{5}{|l|}{ Hematologic factors } \\
\hline \multicolumn{5}{|l|}{ Baseline WBC count } \\
\hline $1-3.9 \times 10^{3}$ cells $/ \mathrm{mm}^{3}$ & $20(21.7)$ & $22(11.9)$ & 11.532 & 0.003 \\
\hline $4-10.9 \times 10^{3}$ cells $/ \mathrm{mm}^{3}$ & $67(72.8)$ & $130(70.7)$ & & \\
\hline$>11 \times 10^{3}$ cells $/ \mathrm{mm}^{3}$ & $5(5.4)$ & $32(17.4)$ & & \\
\hline \multicolumn{5}{|l|}{ Baseline hemoglobin level } \\
\hline$<11.9 \mathrm{~g} / \mathrm{dl}$ & $40(43.5)$ & $74(40.2)$ & 0.233 & 0.629 \\
\hline$\geq 12 \mathrm{~g} / \mathrm{dl}$ & $52(56.5)$ & $110(59.8)$ & & \\
\hline \multicolumn{5}{|l|}{ Current hemoglobin level } \\
\hline$<11.9 \mathrm{~g} / \mathrm{dl}$ & $8(8.7)$ & $12(6.5)$ & 0.431 & 0.511 \\
\hline$\geq 12 \mathrm{~g} / \mathrm{dl}$ & $84(91.3)$ & $172(93.5)$ & & \\
\hline \multicolumn{5}{|l|}{ Immunological factors } \\
\hline \multicolumn{5}{|l|}{ Baseline CD4 count } \\
\hline$<200$ & $65(70.7)$ & $113(61.4)$ & 2.286 & 0.131 \\
\hline$\geq 200$ & $27(29.3)$ & $71(38.6)$ & & \\
\hline \multicolumn{5}{|l|}{ Peak CD4 count } \\
\hline$<200$ & $13(14.1)$ & $9(4.9)$ & 7.137 & 0.08 \\
\hline$\geq 200$ & $79(85.9)$ & $175(95.1)$ & & \\
\hline \multicolumn{5}{|l|}{ Current CD4 count } \\
\hline$<200$ & $40(43.5)$ & $38(20.7)$ & 15.762 & $<0.001$ \\
\hline$\geq 200$ & $52(56.5)$ & $146(79.3$ & & \\
\hline
\end{tabular}

In this study, PLHIV who had a recent CD4 count of fewer than 200 cells $/ \mathrm{mm}^{3}$ had a 3 -fold increased odds of developing virological failure as compared to those with higher CD4 count. This finding was consistent with studies conducted in Ethiopia [11, 28] and Gabon [29]. This might be since clients with a low CD4 count are more likely to 
TABLE 3: Medication-related factors on ART clients at Waghimra zone health institution ART clinic, Northern Ethiopia, in 2019 ( $n=276$ ).

\begin{tabular}{|c|c|c|c|c|}
\hline Variable & Cases $(n \%)$ & Control $(n \%)$ & Chi-square $\left(X^{2}\right)$ & $P$ value \\
\hline $\begin{array}{l}\text { ART regimen at baseline } \\
\text { AZT based } \\
\text { TDF based } \\
\text { D4T based }\end{array}$ & $\begin{array}{l}58(63.1) \\
21(22.8) \\
13(14.1) \\
\end{array}$ & $\begin{array}{l}98(53.3) \\
60(32.6) \\
26(14.1) \\
\end{array}$ & 3.038 & 0.219 \\
\hline $\begin{array}{l}\text { ART regimen at the time of VL testing } \\
\text { AZT based } \\
\text { TDF based }\end{array}$ & $\begin{array}{l}59(64.1) \\
33(35.9) \\
\end{array}$ & $\begin{array}{l}97(52.7) \\
87(47.3) \\
\end{array}$ & 3.251 & 0.071 \\
\hline $\begin{array}{l}\text { Duration on ART in years } \\
<5 \text { years } \\
\geq 5 \text { years }\end{array}$ & $\begin{array}{l}10(10.9) \\
82(89.1) \\
\end{array}$ & $\begin{array}{c}50(27.2) \\
134(72.8)\end{array}$ & 9.583 & 0.002 \\
\hline $\begin{array}{l}\text { Drug toxicity } \\
\text { Yes } \\
\text { No }\end{array}$ & $\begin{array}{ll}32 & (34.8) \\
60 & (65.2)\end{array}$ & $\begin{array}{c}35(19) \\
149(81)\end{array}$ & $\begin{array}{l}8.288 \\
0.567\end{array}$ & $\begin{array}{l}0.004 \\
0.451\end{array}$ \\
\hline $\begin{array}{l}\text { ART shift on first-line drugs } \\
\text { Yes } \\
\text { No }\end{array}$ & $\begin{array}{l}29(31.5) \\
63(68.5)\end{array}$ & $\begin{array}{c}50(27.2) \\
134(72.8)\end{array}$ & & \\
\hline $\begin{array}{l}\text { ART medication adherence } \\
\text { Good } \\
\text { Poor }\end{array}$ & $\begin{array}{l}43(46.7) \\
49(53.3)\end{array}$ & $\begin{array}{c}155(84.2) \\
29(15.8)\end{array}$ & 42.54 & 0.001 \\
\hline $\begin{array}{l}\text { CPT use } \\
\text { Yes } \\
\text { No }\end{array}$ & $\begin{array}{l}72(78.3) \\
20(21.7)\end{array}$ & $\begin{array}{c}134(72.8) \\
50(27.2)\end{array}$ & 0.957 & 0.328 \\
\hline
\end{tabular}

TABLE 4: Clinical-related factors on ART clients at Waghimra zone health institution ART clinic, Northern Ethiopia, in 2019 ( $n=276)$.

\begin{tabular}{|c|c|c|c|c|}
\hline Variable & Cases $(n \%)$ & Control $(n \%)$ & Chi-square $\left(X^{2}\right)$ & $P$ value \\
\hline \multicolumn{5}{|c|}{ Baseline WHO stages } \\
\hline Stage 1 & $2(2.2)$ & $35(19)$ & 38.107 & $<0.001$ \\
\hline Stage 2 & $23(25)$ & $80(43.5)$ & & \\
\hline Stage 3 & $55(59.8)$ & $64(34.8)$ & & \\
\hline Stage 4 & $12(13)$ & $5(2.7)$ & & \\
\hline \multicolumn{5}{|c|}{ Tb coinfection } \\
\hline Yes & $25(27.2)$ & $17(9.2)$ & 15.291 & $<0.001$ \\
\hline No & $67(72.8)$ & $167(90.8)$ & & \\
\hline \multicolumn{5}{|c|}{ An opportunistic infection other than TB } \\
\hline Yes & $34(37)$ & $25(13.6)$ & 19.93 & 0.001 \\
\hline No & $58(63)$ & $159(86.4)$ & & \\
\hline \multicolumn{5}{|c|}{ Baseline BMI $\left(\mathrm{kg} / \mathrm{m}^{2}\right)$} \\
\hline$<16$ & $42(45.7)$ & $46(25)$ & 13.625 & 0.001 \\
\hline $16-18.49$ & $17(18.5)$ & $62(33.7)$ & & \\
\hline$\geq 18.5$ & $33(35.9)$ & $76(41.3)$ & & \\
\hline
\end{tabular}

develop different opportunistic infections, and the added burden of these diseases further complicates their response. This likely increases the possibility of viral mutations and virological failure [30, 31].

The current study also found that PLHIV who stayed for more than 5 years on ART were 3 times more likely to develop virologic failure as compared to those who had less than five years follow-up. This result is supported by different studies conducted in Ethiopia $[11,32]$ and Swaziland [33]. The possible reason might be related to the persistent replication of the virus during ART, and longer time on ART could be associated with drug resistance mutations, which eventually leads to virological failure $[29,34]$.
In this study, adherence to ART was an important determinant of virological failure. PLHIV with poor medication adherence were 4 times more likely to develop virologic failure as compared to clients with good adherence. A metaanalysis finding [35] supports our study, and similar findings were also reported in previous studies conducted in Ethiopia [11, 28, 36] and Zimbabwe [37]. Poor adherence to medication reduces viral suppression due to suboptimal drug concentration and subsequently increasing the viral load $[5,38]$.

The current study found that PLHIV who had experienced drug toxicity were 3.34 times more likely to have virologic failure as compared to those who had not 
TABLE 5: Determinant factors of virologic failure among adult PLHIV attending ART clinic at Waghimra zone health institutions, Northern Ethiopia, in 2019 $(n=276)$.

\begin{tabular}{|c|c|c|c|c|c|}
\hline \multirow{2}{*}{ Variable } & \multicolumn{2}{|c|}{ Virologic failure } & \multirow{2}{*}{ COR $(95 \% \mathrm{CI})$} & \multirow{2}{*}{$\operatorname{AOR}(95 \% \mathrm{CI})$} & \multirow{2}{*}{$P$ value } \\
\hline & Cases & Controls & & & \\
\hline Age of patient & & & & & 0.006 \\
\hline$<35$ years & 41 & 122 & 1 & 1 & \\
\hline$\geq 35$ years & 51 & 62 & $2.45(1.47,4.09)^{*}$ & $2.45(1.29,4.64)$ & \\
\hline \multicolumn{6}{|l|}{ Educational status } \\
\hline None & 53 & 118 & $0.93(0.48,1.80)$ & $1.47(0.63,3.44)$ & 0.369 \\
\hline Primary & 22 & 31 & $1.46(0.66,3.24)$ & $2.32(0.81,6.58)$ & 0.115 \\
\hline Secondary and above & 17 & 35 & 1 & 1 & \\
\hline \multicolumn{6}{|l|}{ Baseline CD4 count } \\
\hline$<200$ & 65 & 113 & $1.51(0.88,2.59)$ & $0.87(0.45,1.68)$ & 0.673 \\
\hline$>200$ & 27 & 71 & 1 & 1 & \\
\hline \multicolumn{6}{|l|}{ Current CD4 count } \\
\hline$<200$ & 40 & 38 & $2.96(1.71,5.10)^{*}$ & $3.06(1.52,6.13)$ & 0.002 \\
\hline$>200$ & 52 & 146 & 1 & 1 & \\
\hline \multicolumn{6}{|l|}{ Duration on art in years } \\
\hline $1-5$ years & 10 & 50 & 1 & 1 & \\
\hline$>5$ years & 82 & 134 & $3.06(1.47,6.37)^{*}$ & $3.11(1.17,8.25)$ & 0.023 \\
\hline \multicolumn{6}{|l|}{ Drug toxicity } \\
\hline Yes & 44 & 53 & $2.26(1.22,3.63)^{*}$ & $3.34(1.54,7.23)$ & 0.002 \\
\hline No & 48 & 131 & 1 & 1 & \\
\hline \multicolumn{6}{|l|}{ Art medication adherence } \\
\hline Good & 43 & 155 & 1 & 1 & \\
\hline Poor & 49 & 29 & $6.09(3.44,10.77)^{* *}$ & $4.24(2.17,8.31)$ & $<0.001$ \\
\hline \multicolumn{6}{|l|}{ TB coinfection } \\
\hline Yes & 25 & 17 & $3.67(1.86,7.22)^{*}$ & $1.82(0.71,4.68)$ & 0.214 \\
\hline No & 67 & 167 & 1 & 1 & \\
\hline \multicolumn{6}{|l|}{ Opportunistic infections other than TB } \\
\hline Yes & 34 & 25 & $3.73(2.05,6.78)^{*}$ & $2.33(0.98,5.35)$ & 0.054 \\
\hline No & 58 & 159 & 1 & 1 & \\
\hline \multicolumn{6}{|l|}{ Baseline BMI } \\
\hline$<16$ & 42 & 46 & $2.1(1.17,3.77)^{*}$ & $1.57(0.76,3.27)$ & 0.223 \\
\hline $16-18.45$ & 17 & 62 & $0.63(0.32,1.24)$ & $0.53(0.23,1.22)$ & 0.137 \\
\hline $18.5-28$ & 33 & 76 & 1 & 1 & \\
\hline \multicolumn{6}{|l|}{ ART regimen at baseline } \\
\hline AZT based & 58 & 98 & $1.18(0.58,2.48)$ & $1.99(0.72,5.54)$ & 0.188 \\
\hline TDF based & 21 & 60 & $0.70(0.31,1.61)$ & $2.14(0.62,7.39)$ & 0.231 \\
\hline D4T based & 13 & 26 & 1 & 1 & \\
\hline ART regimen at the time of VL testing & & & & & 0.940 \\
\hline AZT based & 59 & 97 & $1.61(0.96,2.68)$ & $0.97(0.44,2.15)$ & \\
\hline TDF-based & 33 & 87 & 1 & 1 & \\
\hline
\end{tabular}

experienced drug toxicity. This finding is consistent with a study conducted in Nigeria [39]. This might be due to the fact that clients who have experienced drug toxicity would interrupt ART and causes acquired drug resistance, which leads to virologic failure $[5,40,41]$.

4.1. Limitation of the Study. We used unmatched casecontrol study design, and differences in baseline between the cases and controls may lead to selection bias. Our study may also be affected by survivor bias since deaths and loss to follow-up were not accounted for and may compete with the outcome. The study was entirely based on secondary data, which may affect the reliability of the data.

\section{Conclusion}

This study showed that poor adherence to treatment, longer duration on ART, experiencing drug toxicity, older age, and recent CD $4<200 \mathrm{cell} / \mathrm{mm}^{3}$ were important factors that increase the risk of virologic failure. Therefore, identifying the cause of nonadherence and increasing adherence to ART would help to suppress viral replication. Special attention should be given to older clients, PLHIV with longer time on ART, and low recent CD4 count. Managing the drug toxicity and the use of a safer ART regimen is also an important strategy to prevent virologic failure, besides the promotion of adherence. 


\author{
Abbreviations \\ 3TC: Lamivudine \\ ABC: Abacavir \\ AIDS: Acquired immunodeficiency syndrome \\ ART: Antiretroviral therapy \\ ARV: Antiretroviral \\ AOR: Adjusted odds ratio \\ ATV/r: Atazanavir/ritonavir \\ AZT: Zidovudine \\ BMI: Body mass index \\ CD4: Cluster of differentiation \\ CI: $\quad$ Confidence interval \\ CPT: Cotrimoxazole preventive therapy \\ DTG: Dolutegravir \\ EFV: Efavirenz \\ HC: Health center \\ HIV: Human immunodeficiency virus \\ $\mathrm{LPV} / \mathrm{r}$ : Lopinavir/ritonavir \\ NVP: Nevirapine \\ PLHIV: People living with human immunodeficiency virus \\ SPSS: Statistical Package for Social Sciences \\ TB: Tuberculosis \\ TDF: Tenofovir \\ VL: Viral load \\ WBC: White blood cells \\ WHO: World Health Organization.
}

\section{Data Availability}

The data used to support the findings of this study are available from the corresponding author upon request.

\section{Ethical Approval}

Ethical clearance was obtained from the School of Medicine Institutional Review Board, University of Gondar (Ref. No. SOM/7038/2019). Permission letters were obtained from the Amhara Regional State Health Bureau, Waghimra Zone Health Bureau, and each respective health institution where the data were collected. Personal identifying information was not recorded on the questionnaire, and all information obtained from the clients' chart was kept confidential.

\section{Conflicts of Interest}

The authors declare that they have no conflicts of interest.

\section{Authors' Contributions}

$\mathrm{AE}$ conceived the idea, and the research was designed by $\mathrm{AE}$, $\mathrm{ZA}, \mathrm{ABB}$, and $\mathrm{YA}$. AE coordinated the data collection process. AE and YA analyzed the data. AE, ZA, ABB, and YA wrote the manuscript. All authors read and approved the final manuscript.

\section{Acknowledgments}

The authors would like to thank the University of Gondar for its financial support to conduct the study. The authors are grateful to Amhara Regional State Health Bureau, Waghimra Zone Health Bureau, and respective health institutions' data clerks and card room workers for their cooperation and permission to conduct the study. The authors would like also to extend their gratitude to the supervisors and data collectors.

\section{References}

[1] UNAID, “Global_FactSheet_en.pdf,” 2018, http://www.unaids. org/sites/default/files/media_asset/UNAIDS_FactSheet_en.pdf.

[2] Central Statistics Agency, Ethiopian Demographic and Health Survey, Central Statistics Agency, Addis Ababa, Ethiopia, 2016.

[3] Federal HIV/AIDS Prevention and Control Office, HIV Prevention in Ethiopia National Road Map 2018-2020, Federal HIV/AIDS Prevention and Control Office, Addis Ababa, Ethiopia, 2018.

[4] Ministry of Health, Guideline for Implementation of Antiretroviral Therapy in Ethiopia, Ministry of Health, Addis Ababa, Ethiopia, 2005.

[5] World Health Organization, Consolidated Guidelines on the Use of Antiretroviral Drugs for Treating and Preventing HIV Infection: Recommendations for a Public Health Approach, World Health Organization, Geneva, Switzerland, 2nd edition, 2016.

[6] R. E. Barth, H. A. Tempelman, R. Moraba, and A. I. Hoepelman, "Long-Term Outcome of an HIV-Treatment Programme in Rural Africa: Viral Suppression despite Early Mortality," AIDS Research and Treatment, vol. 2011, Article ID 434375, 5 pages, 2011.

[7] E. Druyts, M. Dybul, S. Kanters et al., "Male sex and the risk of mortality among individuals enrolled in antiretroviral therapy programs in Africa," Aids, vol. 27, no. 3, pp. 417-425, 2013.

[8] W. Kipp, A. Alibhai, L. D. Saunders et al., "Gender differences in antiretroviral treatment outcomes of HIV patients in rural Uganda," AIDS Care, vol. 22, no. 3, pp. 271-278, 2010.

[9] J. B. Nachega, M. Hislop, H. Nguyen et al., "Antiretroviral therapy adherence, virologic and immunologic outcomes in adolescents compared with adults in southern Africa," Journal of Acquired Immune Deficiency Syndromes, vol. 51, no. 1, p. 65, 2009.

[10] L. C. Ivers, D. Kendrick, and K. Doucette, "Efficacy of antiretroviral therapy programs in resource-poor settings: a meta-analysis of the published literature," Clinical Infectious Diseases, vol. 41, no. 2, pp. 217-224, 2005.

[11] B. Bayu, A. Tariku, A. Bulti, Y. Habitu, T. Derso, and D. Teshome, "Determinants of virological failure among patients on highly active antiretroviral therapy in University of Gondar Referral Hospital, Northwest Ethiopia: a case\&ndash;control study," HIV/AIDS-Research and Palliative Care, vol. 9, pp. 153-159, 2017.

[12] A. S. Hassan, H. M. Nabwera, S. M. Mwaringa et al., "HIV-1 virologic failure and acquired drug resistance among first-line antiretroviral experienced adults at a rural HIV clinic in coastal Kenya: a cross-sectional study," AIDS Research and Therapy, vol. 11, no. 1, p. 9, 2014.

[13] L. Taylor-Castillo, G. Herrera-Martínez, M. P. León-Bratti et al., "Study of antiretroviral mutants in HIV patients with treatment failures and the effect of risk factors in the virological failures," Revista do Instituto de Medicina Tropical de São Paulo, vol. 47, no. 6, pp. 327-331, 2005.

[14] D. Wang, C. B. Hicks, N. D. Goswami et al., "Evolution of drug-resistant viral populations during interruption of 
antiretroviral therapy," Journal of Virology, vol. 85, no. 13, pp. 6403-6415, 2011.

[15] J. Izudi, S. Alioni, E. Kerukadho, and D. Ndungutse, "Virological failure reduced with HIV-serostatus disclosure, extra baseline weight and rising CD4 cells among HIV-positive adults in Northwestern Uganda," BMC Infectious Diseases, vol. 16, no. 1, p. 614, 2016.

[16] G. G. Hailu, D. G. Hagos, A. K. Hagos, A. G. Wasihun, and T. A. Dejene, "Virological and immunological failure of HAART and associated risk factors among adults and adolescents in the Tigray region of Northern Ethiopia," PLoS One, vol. 13, no. 5, 2018.

[17] S. Rajasekarana, L. Jeyaseelan, S. Vijilaa, and R. CGaK, "Predictors of failure of first-line antiretroviral therapy in HIV-infected adults: Indian experience," AIDS, vol. 21, no. 4, 2007.

[18] L. Bulage, I. Ssewanyana, V. Nankabirwa et al., "Factors associated with virological non-suppression among HIV-positive patients on antiretroviral therapy in Uganda," $B M C$ Infectious Diseases, vol. 17, no. 1, 2017.

[19] H. D. Meriki, K. A. Tufon, M. H. Afegenwi et al., "Immuno-haematologic and virologic responses and predictors of virologic failure in HIV-1 infected adults on first-line antiretroviral therapy in Cameroon," Infectious Diseases of Poverty, vol. 3, no. 1, p. 5, 2014.

[20] Ethiopian Federal Ministry of Health, National Consolidated Guidelines for Comprehensive HIV Prevention, Care And Treatment, Ethiopian Federal Ministry of Health, Addis Ababa, Ethiopia, 2018.

[21] Amhara Regional Health Bureau, Annual Report, Bahir Dar, Ethiopia, 2018.

[22] T. T. A. Agezew, L. Derseh, and M. Yimer, "Incidence and predictors of first line anti-retroviral therapy failure among adults receiving HIV care in north west Ethiopia: a hospitalbased follow-up study," Journal of Infectious Diseases Epidemiology, vol. 5, no. 2, 2019.

[23] M. Rupérez, C. Pou, S. Maculuve et al., "Determinants of virological failure and antiretroviral drug resistance in Mozambique," Journal of Antimicrobial Chemotherapy, vol. 70, no. 9, pp. 2639-2647, 2015.

[24] M. A. Horberg, L. B. Hurley, D. B. Klein et al., "The HIV care cascade measured over time and by age, sex, and race in a large national integrated care system," AIDS Patient Care and STDs, vol. 29, no. 11, pp. 582-590, 2015.

[25] A. Cescon, C. Cooper, K. Chan et al., "Factors associated with virological suppression among HIV-positive individuals on highly active antiretroviral therapy in a multi-site Canadian cohort," HIV Medicine, vol. 12, no. 6, pp. 352-360, 2011.

[26] J. L. Lu, M. Z. Molnar, A. Naseer, M. K. Mikkelsen, K. Kalantar-Zadeh, and C. P. Kovesdy, "Association of age and BMI with kidney function and mortality: a cohort study," The Lancet Diabetes \& Endocrinology, vol. 3, no. 9, pp. 704714, 2015.

[27] K. P. Cieslak, O. Baur, J. Verheij, R. J. Bennink, and T. M. van Gulik, "Liver function declines with increased age," $H p b$, vol. 18, no. 8, pp. 691-696, 2016.

[28] A. A. Desta, T. W. Woldearegay, N. Futwi et al., "HIV virological non-suppression and factors associated with nonsuppression among adolescents and adults on antiretroviral therapy in northern Ethiopia: a retrospective study," BMC Infectious Diseases, vol. 20, no. 1, p. 4, 2020.

[29] F. Liégeois, C. Vella, S. Eymard-Duvernay et al., "Virological failure rates and HIV-1 drug resistance patterns in patients on first-line antiretroviral treatment in semirural and rural
Gabon," Journal of the International AIDS Society, vol. 15, no. 2, p. 17985, 2012.

[30] F. Kiweewa, A. Esber, E. Musingye, D. Reed, and T. A. Crowell, "HIV virologic failure and its predictors among $\mathrm{HIV}$-infected adults on antiretroviral therapy in the African Cohort Study," PLoS One, vol. 14, no. 2, Article ID e0211344, 2019.

[31] D. Damtie, G. Yismaw, D. Woldeyohannes, and B. Anagaw, "Common opportunistic infections and their CD4 cell correlates among HIV-infected patients attending at antiretroviral therapy clinic of Gondar University Hospital, Northwest Ethiopia," BMC Research Notes, vol. 6, p. 534, 2013.

[32] D. Mulisa, M. Tesfa, G. Mullu Kassa, and T. Tolossa, "Determinants of first line antiretroviral therapy treatment failure among adult patients on ART at central Ethiopia: un-matched case control study," BMC Infectious Diseases, vol. 19, no. 1, p. 1024, 2019.

[33] K. Jobanputra, L. A. Parker, C. Azih et al., "Factors associated with virological failure and suppression after enhanced adherence counselling, in children, adolescents and adults on antiretroviral therapy for HIV in Swaziland," PLoS One, vol. 10, no. 2, Article ID e0116144, 2015.

[34] J. Martinez-Picado and S. G. Deeks, "Persistent HIV-1 replication during antiretroviral therapy," Current Opinion in HIV and AIDS, vol. 11, no. 4, pp. 417-423, 2016.

[35] W. M. Bezabhe, L. Chalmers, L. R. Bereznicki, and G. M. Peterson, "Adherence to antiretroviral therapy and virologic failure: a meta-analysis,” Medicine, vol. 95, no. 15, Article ID e3361, 2016.

[36] M. Ahmed, H. Merga, and H. Jarso, "Predictors of virological treatment failure among adult HIV patients on first-line antiretroviral therapy in Woldia and Dessie hospitals, Northeast Ethiopia: a case-control study," BMC Infectious Diseases, vol. 19, no. 1, p. 305, 2019.

[37] T. Matare, G. Shambira, N. Gombe, M. Tshimanga, and D. Bangure, "Factors associated with human immunodeficiency virus first line treatment failure in Zvishavane district, Zimbabwe, 2014," Austin Journal of HIV/AIDS Research, vol. 2, no. 1, p. 1010, 2015.

[38] S. A. Olowookere, A. A. Fatiregun, M. M. A. Ladipo, E. A. Abioye-Kuteyi, and I. F. Adewole, "Effects of adherence to antiretroviral therapy on body mass index, immunological and virological status of Nigerians living with HIV/AIDS," Alexandria Journal of Medicine, vol. 52, no. 1, pp. 51-54, 2016.

[39] I. O. Abah, N. B. Q. Ncube, H. A. Bradley, O. O. AgbaJi, and P. Kanki, "Antiretroviral therapy-associated adverse drug reactions and their effects on virologic failure- A retrospective cohort study in Nigeria," Current HIV Research, vol. 16, no. 6, pp. 436-446, 2018.

[40] M. C. Prosperi, M. Fabbiani, I. Fanti et al., "Predictors of firstline antiretroviral therapy discontinuation due to drug-related adverse events in HIV-infected patients: a retrospective cohort study," BMC Infectious Diseases, vol. 12, p. 296, 2012.

[41] I. T. Katz, R. Kaplan, G. Fitzmaurice et al., "Treatment guidelines and early loss from care for people living with HIV in Cape Town, South Africa: a retrospective cohort study," PLoS Medicine, vol. 14, no. 11, Article ID e1002434, 2017. 